\title{
Physical Activity and Management of Motor Functions in Tunisian Elderly Adult Affected by Alzheimer's Disease
}

\author{
Sabri Gaied Chortane ${ }^{1}$, Maamer Slimani ${ }^{2}$, Habib Ben Hassen ${ }^{1}$, Firas Zghal ${ }^{1}$ \\ Zouheir Tabka ${ }^{3}$, Lazhar Zorgui ${ }^{4}$ and Foued Chéour ${ }^{4}$ \\ ${ }^{1}$ High Institute of Sport and Physical Education of Sfax, Tunisia \\ ${ }^{2}$ Faculty of Sciences of Bizerte, Tunisia \\ ${ }^{3}$ Faculty of Medicine of Sousse, Tunisia \\ ${ }^{4}$ High Institute of Applied Biology of Médenine, Tunisia
}

\begin{abstract}
The objective of this study was to verify the effects of physical rehabilitation on the decline of Alzheimer's disease in Tunisian male older adult patients. We focused mainly on effects on motor functions mainly stride length, walking speed and postural stability. 21 patients carefully selected were separated into two groups. The first group of nine patients served as control. However, the second group is composed of twelve patients was submitted for six months at three sessions of 60 minutes per week in a physical training program. Our results showed that physical activity improves significantly motor functions in Alzheimer's disease patients, namely stride length, walking speed, double limb support time and postural stability. We conclude that the physical training could be an interesting approach for the control of Alzheimer's disease in Tunisian male older adult patients.
\end{abstract}

Keywords: Alzheimer's disease; physical activity; Tunisian male older adult patients; motor functions.

\section{Introduction}

Alzheimer's disease is a major phenomenon in modern society. Associate in its initial stages with memory disorders, Alzheimer's is a neurodegenerative disease that brings about a variety of cognitive disorders and motor perturbations (Nakamura et al., 1997; Goldman et al., 1999). In addition, although the motor disorders are later and less demonstrative in people with dementia, we attach particular importance. The number of falls in the elderly is estimated that over two millions per year (Robitaille et al., 1990; Vellas et al., 1995), and is responsible for 12,000 deaths. Preventing falls is a major challenge against the dependence of the elderly. In addition, dementia increases the risk of falls (Morris et al., 1987; Tinetti et al., 1995; Van Doorn et al., 2003). Therefore, the maintenance of locomotion capability appears as paramount. First, locomotor efficiency will prevent the fall. Each spatio-temporal gait parameters such as walking speed, double limb support time and stride length are valuable indicators of the risk of falls (O'Keeffe et al., 1996; Van Iersel et al., 2004; Merory et al., 2006). On the other hand, walking is an activity of daily life often associated with one or more cognitive activities which puts the person in double or triple task, often difficult to negotiate. Indeed, intentional cost during different tasks being higher in the person with dementia, the risk of fall increases in the activities of daily life (Sheridan et al., 2003). The gait disorders appear as a common denominator of risk of falls of demented patients. Walking thus appears as a parameter to maintain as long as possible in these patients. Motor dysfunction in Alzheimer's disease is a late symptom and may appear in the form of extrapyramidal signs and abnormal gait, resulting in immobilization (Bottin et al., 2002; Ramos et al., 2005). The motor changes can manifest themselves in many different forms and stages of Alzheimer's disease. Since walking and balance are complex activities that require the integration of motor, sensory systems, brain processes and the reduction of the walking speed and the deficit of the balance typically emerge in the early first stages of dementia and cognitive disabilities apparent (Franssen et al., 1999; Wang et al., 2006).

Motor dysfunctions in patients with Alzheimer's disease can affect posture and posture control, with a significant reduction in engine speed (Alexander et al., 1995; Pettersson et al., 2002). These changes could be explained by a contribution of the various impairments coupled with delays in the activation of the central nervous system responses leading to postural perturbations including loss of neurons, dendritic loss, lower metabolism and cerebral perfusion and modification of neurotransmitter synthesis (Kluger et al., 1997; Franssen et al., 1999).

Some studies have shown that physical activity has a beneficial effect on executive functions (Scherder et al., 2005; Eggermont et al., 2006), on cognitive functions (Palleschi et al., 1996) and communication skills of elderly people with mild cognitive impairment or dementia of the Alzheimer type (Friedman and Tappen, 1991). Wang et al. (2006) was shown that regular physical activity was associated to a lower risk of developing dementia, suggesting that physical exercise offers cognitive benefits due to the connection between cognitive and motor functions. Thus, improving patient's physical condition may extend their independence with regard to 
mobility, thereby improving quality of life for themselves and caregivers, despite the progression of the disease (Teri et al., 2002; Pettersson et al., 2005). As for our study, it shows a positive impact of such activity on locomotor efficiency in our patients, which may consequently diminish the risk of falling, as was shown by Toulotte et al. (2004) in the healthy elderly. Similarly, Rolland et al. (2007) have shown the effect of a physical activity program of walking type increase balance and posture of older adults with Alzheimer's disease.

Existing pharmacological treatments are a valuable help in the management of some symptoms associated with the disease, but, in any case to stop permanently the progression of dementia. Catches in nondrug load appear to offer a promising therapeutic track that no of them do not benefit from a universally recognized efficacy. Nevertheless, both forms of therapy emerge other in terms of efficiency; therapies focus on cognition, including cognitive stimulation therapies and centered on a physical drive capabilities (Sellal and Kruckzek, 2007).

The objective of this study was to verify the effects of physical rehabilitation of six months at three sessions of 60 minutes per week on the decline of Alzheimer's disease in Tunisian male older adult patients. We are interested primarily affect motor functions mainly stride length, walking speed and postural stability.

\section{Materials and methods}

Patients

Before starting the experiment, we had to get in first approved by the Committee for the Protection of Persons (CPP) in the region of Monastir, Tunisia, whose mission is to judge the scientific quality of the project and ensure the safety of people who will attend. And the study was conducted on a population of 21 Tunisian male older adult patients $(63.0 \pm 4.2$ years $)$ with Alzheimer's disease and this carefully selected to assess the effects of physical activity on walking, and balance and the risk of falls is to say about the decline of Alzheimer's disease. We formed two groups of patients on a voluntary basis and according to our following inclusion criteria, cognitively by the score at the Mini Mental State Examination (MMSE) of Folstein (1975) and the motor plan by the ability to walk $10 \mathrm{~m}$ and balance and risk of falling measured by the Berg Balance Scale (BBS). Elderly wheelchair and/or with severe hearing or vision problems, behavioral disorders incompatible with the intervention were excluded from the study. The MMSE is the test as to the inclusion or exclusion of people from the study. A score below 30 is generally regarded as the threshold for dementia. We are talking about mild dementia between 19-30, moderate dementia between 10-18 and severe dementia below 10. For our study, we selected those who scored between 7 and 20. This test, no doubt most used in clinical practice allows identifying cognitive impairment, but does not exempt research diagnostic criteria for dementia.

\section{Physical training program}

Our study was conducted over a period of 24 weeks. The first and last two were reserved for cognitive and motor assessments. During the other 20 weeks, patients underwent three sessions of rehabilitation of one hour per week. During the first two weeks of the training program, participants were introduced to physical activities involving joint mobilization and muscle stimulation. The assessment of individual skills is the first step of orientation programming to define the individual motor profile of participants. Then, for the remaining 15 weeks, we have developed a system based on walking exercise program, balance and endurance exercises. Three themes were addressed by trading in accordance with our goals, and were subject to 40 minutes of exercises per session. One session per week was reserved for walking and improvement of gait parameters through exercises types motor route athletic 'or walk lengthier exercises' mini-golf adapted' for example. Then, another session a week was devoted to endurance exercises including exercises on arm ergometer (15-20 minutes) and legs (15-20 minutes). In this way participants could thus maintain a slight effort to moderate for a long period. During this effort the patients were fitted with a heart rate monitor Beurer glove P-100. While we have not been able to achieve a stress test, we determined the target heart rate between 60 and $70 \%$ of maximum heart rate. The last session of the week involves activities that combine endurance, balance and walking. This pleasant supposed session and its purpose is to maintain motivation throughout the program period. Time is divided into three parts. The first consists of $10 \mathrm{~min}$ of contact, joint mobilization and warming. The second part is $40 \mathrm{~min}$ activity as described above. The third part is $10 \mathrm{~min}$ corresponds to a return to calm and relaxation.

\section{Mini Mental State Examination (MMSE)}

We have evaluated the MMSE of patients before and after training. The MMSE is a brief test (approximately ten minutes) that can be used for screening for cognitive impairment and for estimating severity and progression of Alzheimer's disease and before and after other forms of dementia. The maximum score on the MMSE test is 30. Age and education levels may influence scores. Scores above 20 can suggest mild cognitive impairment, scores between 11 and 20 suggest moderate cognitive impairment and scores of ten or below suggest severe cognitive impairment. These scores are suggested in the context that a patient has already been clinically diagnosed with Alzheimer's disease and a level of cognitive impairment is to be ascertained (Folstein et al., 1975). 


\section{Berg Balance Scale (BBS)}

Functional balance was assessed using the Berg Balance Scale (BBS) (Berg et al., 1992; Myamoto et al., 2004). This scale consists of assessing an individual's performance on 14 common tasks of daily living that challenge functional balance in an increasing degree of difficulty, ranging from remaining seated with no back rest, to picking up an object from the floor, reaching forward and standing on one foot. The score ranges from 0 to 56 points, higher scores denoting better performance.

\section{Walking assessment}

The analysis of walking was performed with a Bessou locometer (Bessou et al., 1988) and SATEL software. The principle of this data analysis method consists of recording the longitudinal movement of each foot during an approximately $10 \mathrm{~m}$ long walk. The movement of each foot was transmitted, by means of a thread, to an optical sensor. The spatiotemporal data of a walking cycle were recorded. The phases of acceleration and deceleration were eliminated to ensure that the calculated values corresponded to the stabilized speed (Bessou et al., 1988). Prior to walking, the patient was seated on a chair to facilitate strap installation. The patient's feet were in contact with the locometer, and the threads were switched on. Following these verifications, the patient stood up and walked the $10 \mathrm{~m}$ at a comfortable speed. A chair was set up at that distance to provide a demented individual with a reference point and to facilitate removal of the straps. The parameters selected were walking speed, stride length and double limb support time.

\section{Results}

Table 1 shows the cognitive and motor functions baseline levels of Tunisian male older adult patients with Alzheimer's disease belonging to the control group and training group. It specifies the memory abilities of patients assessed by the MMSE, balance and fall risk in connection with the bodily function as estimated by the test BBS activity, walking speed, stride length and the double limb support time. The Mann-Whitney U test on the two samples showed no statistically significant difference at $\alpha=0.05$ between the two groups of patients at the beginning of the rehabilitation program and this for all cognitive and motor functions assessed.

Table 1. Baseline means value \pm SD according to the cognitive and motor functions in Tunisian male older adult patients with Alzheimer's disease belonging to control group and training group.

\begin{tabular}{lrr}
\hline Functions & Exercise group & Control group \\
\hline MMSE & $19.80 \pm 2.03$ & $19.40 \pm 2.03$ \\
BBS & $47.60 \pm 1.60$ & $47.40 \pm 1.60$ \\
Walking speed (m/s) & $0.75 \pm 0.12$ & $0.82 \pm 0.20$ \\
Stride length (m) & $0.96 \pm 0.24$ & $0.97 \pm 0.10$ \\
Double support time (s) & $3.23 \pm 2.64$ & $03.56 \pm 3.54$ \\
\hline MMSE = Mini Mental State Examination; BBS: Berg Balance Scale.
\end{tabular}

Figures 1, 2, and 3 show the evolution of BBS levels, the walking speed and stride length of Tunisian male older adult patients with Alzheimer's disease in the control group and training group for six months at three sessions of 60 minutes per week. The nonparametric statistical test 'Wilcoxon Signed Rank has been used to verify the significance of changes in cognitive and motor functions of patients measured before and after six months of rehabilitation.

The balance, risk of falls and postural stability of patients physically trained group improved significantly after the rehabilitation period of six months at three sessions of 60 minutes per week. However, they decrease in the control group ( $\operatorname{Pr} \leq 0.05$; Figure 1). This indicates that physical exercise improves motor function 'BBS' of patients with Alzheimer's disease.

Stride length of patients physically trained group increased significantly after the rehabilitation period of six months at three sessions of 60 minutes per week. However, it decreased in the control group $(\operatorname{Pr} \leq 0.05$; Figure 2). This indicates that physical exercise improves motor function 'Stride length' of patients with Alzheimer's disease.

Walking speed of patients physically trained group increased significantly after the rehabilitation period of six months at three sessions of 60 minutes per week. However, it decreased in the control group $(\operatorname{Pr} \leq 0.05$; Figure 3). This indicates that physical exercise improves motor function 'Walking speed' of patients with Alzheimer's disease. 


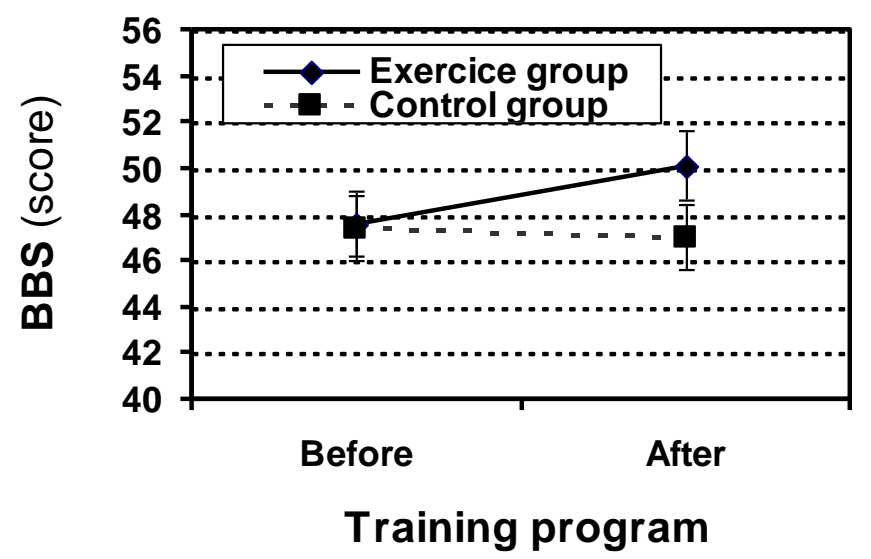

Figure 1. Evolution of the Berg Balance Scale (BBS) levels in Tunisian male older adult patients with Alzheimer's disease belonging to the control group or to the training group. Mean values \pm SD for 9-11 patients.

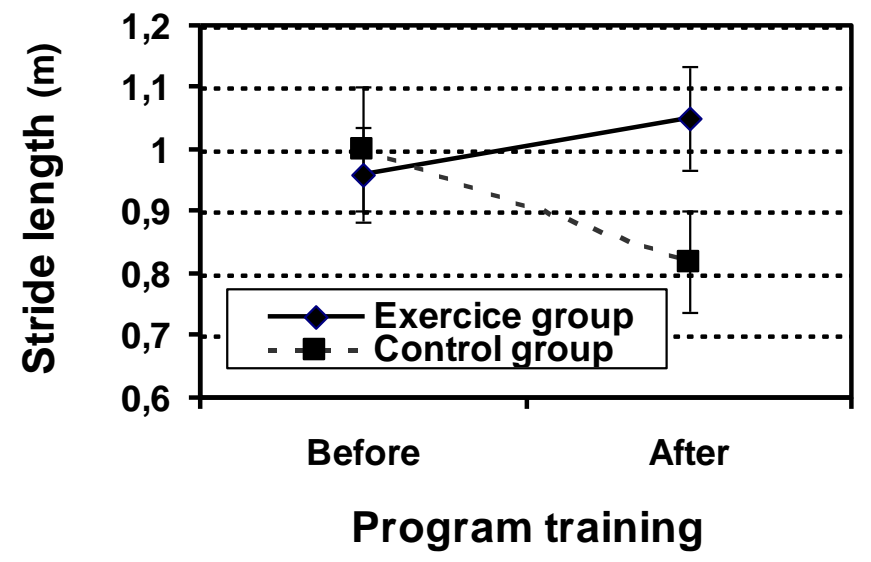

Figure 2. Evolution of stride length levels in Tunisian male older adult patients with Alzheimer's disease belonging to the control group or to the training group. Mean values \pm SD for 9-11 patients.

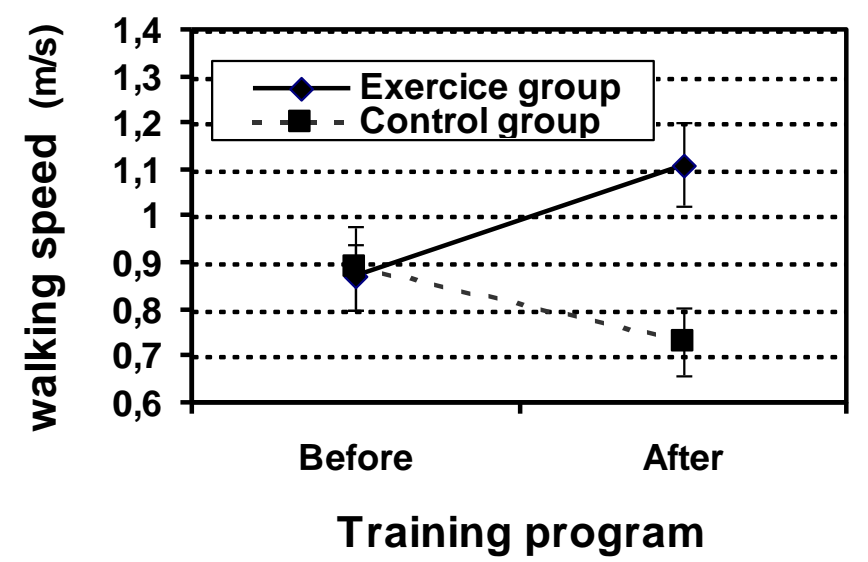

Figure 3. Evolution of walking speed levels in Tunisian male older adult patients with Alzheimer's disease belonging to the control group or to the training group. Mean values \pm SD for 9-11 patients.

\section{Discussion}

Alzheimer's is a neurodegenerative disease. It is characterized by the progressive and irreversible degeneration of nerve cells. The loss of these cells leads to the continuous decline in cognitive abilities formerly known intellectual abilities synthesis (Kluger et al., 1997; Franssen et al., 1999). Is often associated with Alzheimer disease to memory loss because they are the neurons located in the region of the hippocampus, the 
seat of memory, which is the first to be affected. But gradually other areas of the brain are affected, resulting in impaired use of language orientation in time and space capabilities, recognition of objects and people, of reasoning, of balance and posture etc. These disorders progressively reduce autonomy (Rolland et al., 2007). Indeed, it has been shown that when certain pathological processes affecting the central nervous system, there appears fluctuation of gait parameters related to falls risk. On the other hand, discrepancies of walking people with dementia generate a reduction in mobility and an increase in falls (Morris et al., 1987; Van Doorn et al., 2003). The risks of falls are doubly increased in the demented elderly. So, dementia and cognitive impairment increases the risk of falls (Van Doorn et al., 2003; Sheridan and Hausdorff, 2007).

Physical activity is considered an effective method for the management of cognitive functions of people with Alzheimer's (Chortane et al., 2014). However, its effects on the motor skills such as posture and walking ... have not been mentioned. It is in this context that the work has been developed. Indeed, our study has shown that physical activity based on walking exercises, balance and endurance increases the level of mnemic capacity, maintaining posture and balance, stride length, and walking speed of Tunisian male older adult patients with Alzheimer's disease. These results are consistent with the results obtained by Palleschi et al. (1996) and Rolland et al. (2000, 2007) who reported that endurance exercises (walking or cycle ergometer) improve overall cognitive functions assessed by the MMSE, walking and balance of people with senile dementia of the Alzheimer type. Also, Santana-Sosa et al. (2008) confirmed that a physical activity programs significantly improve muscle strength, flexibility, agility, dynamic balance, endurance, walking and decrease the risk of falls due to a 12 weeks. The value of an exercise program on the improvement of physical parameters in the elderly has also been reported (Wild et al., 1992; Shigematsu et al., 2002; Toulotte et al., 2004; Shen et al., 2008). Physical activity thus it's important in improving the spatio-temporal parameters of gait and balance (Sherrington et al., 2008; Thomas et al., 2010).

In conclusion, this study shows that the physical rehabilitation of Tunisian male older adult patients with Alzheimer's disease for six months at three sessions of 60 min per week significantly improves their motor functions, ie stride length, walking speed and postural stability.

\section{References}

[1]. Alexander NB., Mollo JM., Giordani B. 1995. Maintenance of balance, gait patterns, and obstacle clearance in Alzheimer's disease. Neurology, 45: 908-914.

[2]. Alzheimer Disease International (ADI). 2009. World Alzheimer Report 2009 [en ligne]. London: Prince M., Jackson J., 2009, 96p. Disponible sur: http:// www.alz.co.uk/research/worldreport/ (consulté le 05.05.2010).

[3]. Arbez N. 2005. Etude des effets des peptides amylö̈des: du fonctionnement de la synapse aux modifications du cytosquelette dans l'apoptose neuronale [thèse en ligne]. Biologie du vieillissement. Paris 5 (France): Université René Descartes, 2005,253 p.

[4]. Berg KO., Wood-Dauphinee SL., Williams JI., Maki B. 1992. Measuring balance in the elderly: validation of an instrument. Canadian journal of public health, 83: 7-11.

[5]. Bessou P., Dupui P., Montoya R., Pagès B., 1988. Simultaneous recording of longitudinal dis- placements of both feet during human walking. Journal of Physiology, 83: 102-110.

[6]. Clement JP. 2007. Facteurs de risque et facteurs protecteurs des démences. Morphologie, 91: 207-20.

[7]. Chortane SG, Zorgui L., Slimani M., Dogui M., Gazzah M., Chéour F. 2014. Physical activity and management of Alzheimer's disease in Tunisian male older adult patients. IOSR Journal of Dental and Medical Sciences (IOSR-JDMS), 5: 74-78.

[8]. Chtioui-Bastien V. 2001. Maladie d'Alzheimer: traitements actuels et perspectives d'avenir. Ph.D: Pharm : Université du Droit et de la Santé de Lille 2: $2001 ; \mathrm{n}^{\circ}$ 50378DE200145, 155f.

[9]. Cummings JL. 2004. Alzheimer's disease. New England Journal of Medicine, 351: 56-67.

[10]. Fisher BE., Wu AD., Salem GJ., Song J., Lin CH., Yip J., Cen S., Gordon J., Jakowec M., Petzinger G. 2008. The effect of exercise training in improving motor performance and corticomotor excitability in people with early Parkinson's disease. Archives of Physical Medicine and Rehabilitation, 89: 1221-1229.

[11]. Folstein MF., Folstein SE., Mchugh PR. 1975. Mini-mental state. A practical method for grading the cognitive patients for the clinician. Journal Psychiatry research, 12: 189-198.

[12]. Franssen EH., Souren LEM., Torossian CL., Reisberg B. 1999. Equilibrium and limb coordination in mild cognitive impairment and mild Alzheimer's disease. Journal of the American Geriatrics Society, 47: 463-469.

[13]. Goldman WP., Baty JD., Buckles VD., Sahrmann S., Morris JC. 1999. Motor dysfunction in mildly demented AD individuals without extrapyramidal signs. Neurology, 53: 956-962.

[14]. Helmer C., Pasquier F., Dartigues JF. 2006. Epidémiologie de la maladie d'Alzheimer et des syndromes apparentés. Médecine/Sciences, 22: 288-96.

[15]. Herman T., Giladi N., Gruendlinger L., Hausdorff JM. 2007. Six weeks of intensive treadmill training improves gait and quality of life in patients with Parkinson's disease: a pilot study. Archives of Physical Medicine and Rehabilitation, 88: 1154-1158.

[16]. Hothorn T., Hornik K. 2010. ExactRankTests: exact distributions for rank and permutation tests. R package version 0.8-19. Retrieved from www.CRAN.R project.org/package=exactRankTests.

[17]. Kluger A., Gianutsos JG., Golomb J. 1997. Patterns of motor impairment in normal aging, mild cognitive decline, and early Alzheimer disease. The journals of gerontology. Series B, Psychological sciences and social sciences, 52: 28-39.

[18]. Myamoto ST., Lombardi JI., Berg KO., Ramos LR., Natour J. 2004. Brazilian version of the Berg Balance Scale. Brazilian Journal of Medical and Biological Research, 37: 1411- 1421.

[19]. Merory J., Wittwer JE., Rowe, CC, Webster KE. 2006. Quantitative gait analysis in patients with dementia with Lewy bodies and Alzheimer's disease. Gait Posture, 414- 419.

[20]. Morris JC, Rubin EH, Morris EJ, Mandel SA. 1987. Senile dementia of the Alzheimer's type. An important risk factor for serious falls. The Journals of Gerontology, 42: 412-417.

[21]. Nachar N. 2008. The Mann-Whitney U: A test for assessing whether two independent samples come from the same distribution. Tuturials in Qunatitative Methods for Psychology, 4: 13-20. 
[22]. Nakamura T., Meguro K., Yamazaki H., Okuzumi H., Tanaka A., Horikawa A., Yamaguchi K., Katsuyama N., Nakano M., Arai H., Sasaki H. 1997. Postural and gait disturbance correlated with decreased frontal cerebral blood flow in Alzheimer disease. Alzheimer Disease and Associated Disorders, 11: 132-139.

[23]. O'keeffe ST., Kazeem H., Philpott M., Playfer L., Gosney M., Lye M. 1996. Gait disturbance in Alzheimer's disease: A Clinical Study. Age and Ageing, 25: 313-316.

[24]. Palleschi L., Vetta F., deGennaro E., Idone G., Sottosanti G., Gianni W., Marigliano V. 1996. Effects of aerobic training on the cognitive performance of elderly patients with senile dementia of the Alzheimer type. Archives of Gerontology and Geriatrics, 5: 47-50.

[25]. Pettersson AF., Engardt M., Wahlund L. 2002. Activity level and balance in subjects with mild Alzheimer's disease. Dementia and Geriatric Cognitive Disorders, 13: 213-216.

[26]. Ramos-Cerqueira ATA., Torres AR., Crepaldi AL., Oliveira NIL., Scazufca M., Menezes PR., Prince M. 2005. Identification of dementia cases in the community: A Brazilian experience. Journal of the American Geriatrics Society, 53: 1738-1742.

Robitaille Y., O’Loughlin J. 1990. Épidémiologie de la chute chez les personnes âgées. L'année gérontologique. Pp. 145-55.

[27]. Rolland Y., Rival L., Pillard F., Lafont C., Riviere D., Albarede JL., Vellas B. 2000. Feasibily of regular physical exercice for patients with moderate to severe alzheimer disease. The Journal of nutrition, health and aging, 4: 109-113.

[28]. Rolland Y., Pillard F., Klapouszczak A., Reynish E., Thomas D., Andrieu S., Rivière D., Vellas B. 2007. Exercise program for nursing home residents with Alzheimer's disease: a 1-year randomized, controlled trial. Journal of the American Geriatrics Society, 55: $158-165$.

[29]. Santana-Sosa E., Barriopedro MI., López-Mojares LM., Pérez M., Lucia A. 2008. Exercise training is beneficial for Alzheimer's patients. International Journal of Sports Medicine, 29: 845-850.

[30]. Sauvage LR., Myklebust BM., Crow-Pan J., Novak S., Millington P., Hoffman MD., Hartz AJ., Rudman D. 1992. A clinical trial of strengthening and aerobic exercise to improve gait and balance in elderly male nursing home residents. American Journal of Physical Medicine and Rehabilitation, 71: 333-342.

[31]. Schenk F., Leuba G., Bula C. 2004. Du vieillissement cérébral à la maladie d'Alzheimer : autour de la notion de plasticité. Bruxelles: Editions De Boeck Université, 2004, 338 p. (Neurosciences et cognition) ISBN 2-8041-4595-6.

[32]. Scherder EJ., Van Paasschen J., Deijen JB., Van Der Knokke S., Orlebeke JF., Burgers I., Devriese PP., Swaab DF., Sergeant JA. 2005. Physical activity and executive functions in the elderly with mild cognitive impairment. Aging and Mental Health, 9: 272280.

[33]. Sellal F., Kruckzek E. 2007. Maladie d'Alzheimer. 2e éd. Rueil-Malmaison : Doin, 2007, 152 p. (Collection Conduites). ISBN 9782-7040-1211-4.

[34]. Sevalle J. 2008. Etude de la production et de la dégradation du peptide amyloïde dans la maladie d'Alzheimer [thèse en ligne]. Biologie moléculaire et cellulaire. Nice (France) : Université de Nice-Sophia Antipolis, 2008, 193 p. Disponible sur : http://tel.archivesouvertes. fr/docs/00/41/93/65/PDF/J.SEVALLE_2008-12-01.pdf (consulté le 23.02.2010).

[35]. Shen CL., James CR., Chyu MC., Bixby WR., Brismée JM., Zumwalt MA., Poklikuha G. 2008. Effects of tai chi on gait kinematics, physical function, and pain in elderly with knee osteoarthritis. A pilot study. The American Journal of Chinese Medicine, 36: 219-232.

[36]. Sheridan PL., Hausdorff JM. 2007. The role of higher-level cognitive function in gait: executive dysfunction contributes to fall risk in Alzheimer's disease. Dementia and Geriatric Cognitive Disorders, 24: 125-37.

[37]. Sherrington C., Pamphlett PI., Jacka JA., Olivetti LM., Nugent JA., Hall JM. 2008. Group exercise can improve participants' mobility in an outpatient rehabilitation setting: a randomized controlled trial. Clinical Rehabilitation, 22: 493-502.

[38]. Shigematsu R., Chang M., Yabushita N., Sakai T., Nakagaichi M., Nho H., Tanaka K. 2002. Dance-based aerobic exercise may improve indices of falling risk in older women. Age and Ageing, 31: 261-266.

[39]. Tappen RM., Roach KE., Applegate B., Stowell P. 2000. Effect of a combined walking and conversation intervention on functional mobility of nursing home residents with Alzheimer disease. Alzheimer Disease and Associated Disorders, 14: 196-201.

[40]. Teri L., Gibbons LE., McCurry SM. 2003. Exercise plus behavioral management in patients with Alzheimer disease: a randomized controlled trial. Journal of the American Medical Association, 290: 2015-2022.

[41]. Thomas S., Mackintosh S., Halbert J. 2010. Does the 'Otago exercise programme' reduce mortality and falls in older adults ?: A systematic review and meta analysis. Age and Ageing, 39: 681-687.

[42]. Tinetti ME., Doucette J., Claus E., Marottoli R. 1995. Risk factors for serious injury during falls by older persons in community. Journal of the American Geriatrics Society, 43: 1214-1221.

[43]. Touchon J., Portet F. 2004. La maladie d'Alzheimer. 3e éd. Issy-les-Moulineaux: Masson; Levallois-Perret : Le Quotidien du médecin, 2004, 177 p. (Consulter/prescrire) ISBN 2-294-01967-9

[44]. Toulotte C., Thévenon A., Fabre C. 2004. Effets d'un entraînement physique sur l'équilibre statique et dynamique chez des sujets âgés chuteurs et non-chuteurs. Annales de réadaptation et de médecine physique. Pp. 604-610.

[45]. Van Doorn C., Gruber-Baldini AL., Zimmerman S., Hebel JR., Port CL., Baumgarten M., Quinn CC., Taler G. 2003. Dementia as a risk factor for falls and fall injuries among nursing home residents. Journal of the American Geriatrics Society, 51: $1213-1218$.

[46]. Van Iersel MB., Hoefsloot W., Munneke M., Bloem BR., Olde Rikkert MG. 2004. Systematic review of quantitative clinical gait analysis in patients with dementia. Archives of Gerontology and Geriatrics, 37: 27-32.

[47]. Vellas BJ., Faisant C., Lauque S. 1995. Étude ICARE : investigation sur la chute accidentelle, recherche épidémiologique. L’année gérontologique. Pp. 423-436.

[48]. Wang L., Larson EB., Bowen JD., VanBelle G. 2006. Performance- based physical function and future dementia in older people. Archives of Internal Medicine, 166: 1115-1120.

[49]. Wei W., Norton DD., Wang X., Kusiak JW. 2002. A $\beta$ 17-42 in Alzheimer's disease activates JNK and caspase-8 leading to neuronal apoptosis. Brain, 125: 2036-43. 